\title{
Hematological Risk Factors for Coronary Heart Disease
}

\author{
Mohsen A.F. El-Hazmi \\ Medical Biochemistry Department and WHO Collaborating Centre, College of Medicine and King Khalid Hospital, \\ King Saud University, Riyadh, Saudi Arabia
}

\begin{abstract}
Key Words
Coronary heart disease - Antithrombin III deficiency . Protein C · Protein S · Factor V Leiden . Prothrombin . Homocysteine $\cdot$ Fibrinogen
\end{abstract}

\begin{abstract}
Coronary heart disease (CHD) is a leading cause of morbidity and mortality in the developed and developing countries. Several underlying genetic and environmental factors have been implicated in its etiology. Some of the hematological risk factors implicated in the development of coronary heart disease include antithrombin III deficiency, protein $\mathrm{C}$ and protein $\mathrm{S}$ deficiency, factor $\mathrm{V}$ Leiden mutation, prothrombin gene (20210A) mutation hyperhomocystinaemia, elevated factor VIII levels, plasminogen activator inhibitor type 1 and dysfibrinogenaemia. In general, these factors result in thrombosis, thus having a negative effect on the heart and blood vessels. This paper presents an overview of some of the hematological risk factors involved in the development of CHD.
\end{abstract}

Copyright $\odot 2002$ S. Karger AG, Basel

\section{Introduction}

Coronary heart disease is a frequently encountered multifactorial disorder and is recognized as a major cause of morbidity and mortality both in developed and devel- oping countries [1]. Table 1 presents cardiovascular disease death rate in some countries of the world. Interactions between genetic and environmental factors contribute to the development of coronary heart disease.

One of the largest prospective studies, the Framingham Study initiated in 1948 has provided insight into the prevalence, incidence, full clinical spectrum and predisposing factors for coronary heart disease [2]. It coined the term 'risk factors' and listed the 'traditional risk factors' for development of coronary heart disease [2]. Thus, the risk factors for CHD can now be classified as (i) traditional (established) risk factors, and (ii) non-traditional (novel) risk factors. Both traditional and non-traditional risk factors are listed in figure $1[2,3]$ and a negative risk factor is high-density lipoprotein-cholesterol (HDL-cholesterol) when its level is equal to or greater than $60 \mathrm{mg} / \mathrm{dl}$ $(\geq 1.6 \mathrm{mmol} / \mathrm{l})$.

Interest in the non-traditional risk factors became important when it was realized that the well-known traditional factors failed to explain the high incidence of coronary heart disease in different populations [3]. Over the last decade the search for novel risk factors has been actively pursued and interesting facts have emerged.

\section{Arteriosclerosis and Coronary Heart Disease}

A common mechanism underlying the development of CHD seems to be arteriosclerosis which is associated with thickening of the intima due to a combination of fibrosis,

\begin{tabular}{ll}
\hline KARGER & ( ) 2002 S. Karger AG, Basel \\
$1011-7571 / 02 / 0116-0056 \$ 18.50 / 0$ \\
$\begin{array}{l}\text { Fax +4161306 12 34 } \\
\text { E-Mail karger@karger.ch } \\
\text { www.karger.com }\end{array}$ & $\begin{array}{l}\text { Accessible online at: } \\
\text { www.karger.com } / \mathrm{mpp}\end{array}$
\end{tabular}

Prof. Mohsen A.F. El-Hazmi

Medical Biochemistry Department and WHO Collaborating Centre

College of Medicine and King Khalid Hospital, King Saud University

PO Box 2925, Riyadh 11461 (Saudi Arabia)

Tel. +96614670830, Fax +96614672575, E-Mail mohsen@ksu.edu.sa 
Fig. 1. Cardiovascular risk factors.

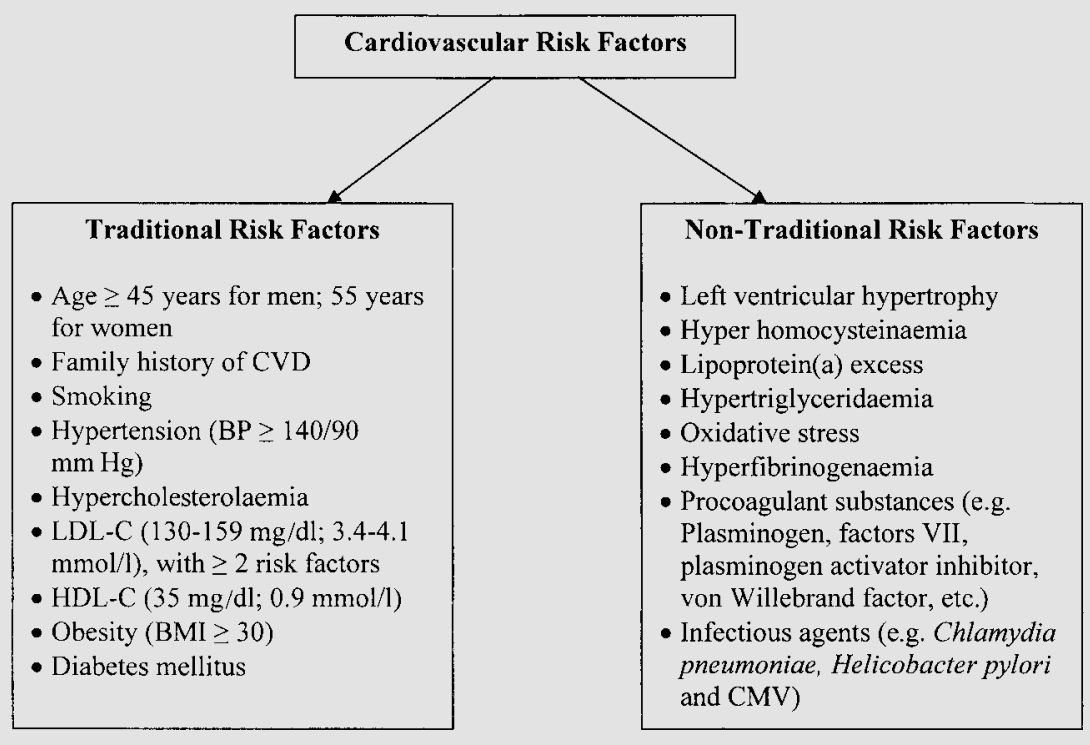

Table 1. Cardiovascular disease death rates in some countries ${ }^{1}$

\begin{tabular}{lllll}
\hline & Total CVD & IHD $(\%)^{3}$ & CD $(\%)^{3}$ & Others $(\%)^{3}$ \\
\hline Scotland & 435.1 & 59.3 & 25.9 & 14.8 \\
Austria & 382.4 & 39.5 & 26.5 & 35.2 \\
Sweden & 368.1 & 56.8 & 16.7 & 24.5 \\
USA & 375.4 & 52.6 & 15.0 & 32.3 \\
Italy & 324.5 & 30.0 & 31.5 & 38.5 \\
Switzerland & 288.8 & 37.9 & 19.8 & 42.3 \\
Japan & 226.5 & 16.7 & 39.8 & 43.5 \\
France & 215.2 & 29.8 & 27.5 & 42.7 \\
\hline
\end{tabular}

\section{WHO Report.}

Age standardized death rate per 100,000.

$\%$ of total CVD. IHD = Ischemic heart disease CVD = cardiovascular disease; Others = other acute MI.

smooth muscle cell proliferation and the development of an intercellular lipid core [4]. Most of the traditional risk factors are shown to contribute to the initial events and towards the progression of coronary heart disease [5]. Formation of arteriosclerosis results from accumulation of deposits on the inside of arterial walls leading to narrowing or clogging of the arterial lumen. Intimal layer injury attracts cholesterol deposits, macrophages and calcium salts, which leads to formation of scar-like fibrous tissue forming an atherosclerotic plaque [5]. The occlusion or blocking of the arteries occurs either by large atherosclerotic plaques or thrombosis. The thrombus formation is frequently due to secondary formation of blood clots by platelets blocking the flow of blood. The formation and accumulation of what are known as foam cells in the intima is the hallmark of the early atherosclerotic lesion. These 'foam cells' are believed to be derived from macrophages and smooth muscle cells and the atherosclerotic lesion is promoted by two blood cells, i.e. macrophages and platelets. Figure 2 lists the prothrombotic risk factors and figure 3 schematically presents the pathophysiological mechanism by which coronary risk factors lead to atherosclerosis.

\section{Traditional Risk Factors for CHD Development}

Extensive studies have confirmed the role of the traditional risk factors in the development of CHD. Each of these factors contributes significantly and the additive effect is obvious when two or more of these factors are co-existent [6]. A major factor is the hypercholesterolaemia associated with elevated LDL-cholesterol and a low level of HDL-cholesterol. Increased circulating cholesterol is believed to increase the risk of oxidative disease process due to its susceptibility to oxidation while in circulation. The low density lipoproteins are cholesterol-rich particles with a life span of about 2.5 days. They carry 
Fig. 2. Genetic prothrombotic risk factors for CHD.

Fig. 3. Pathophysiological mechanism by which coronary risk factors lead to athero-

sclerosis.
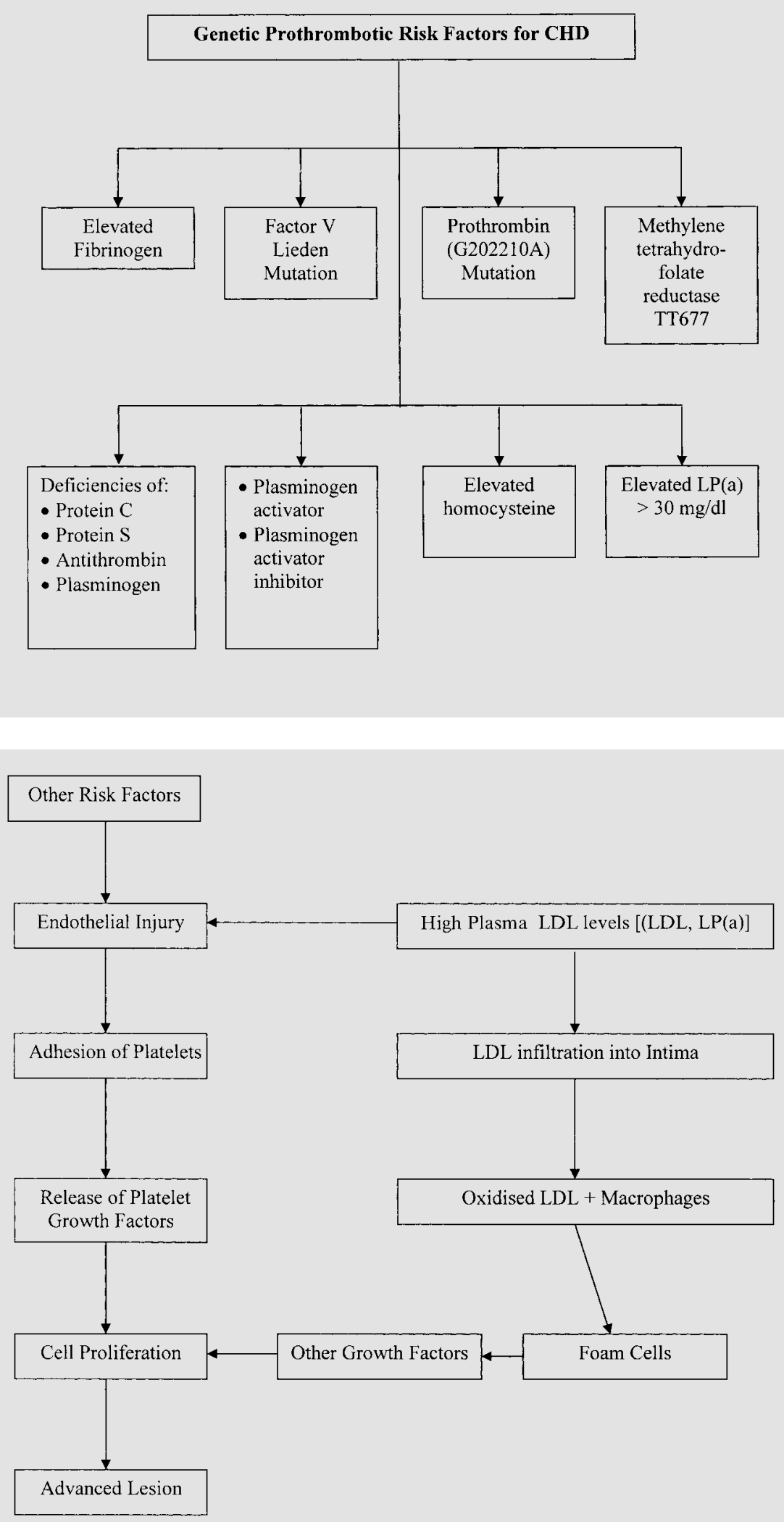
almost $45 \%$ cholesterol, 20\% triglycerides, 23\% phospholipids and 20\% proteins, which are mainly Apo-B (95\%). LDL-cholesterol is the major vehicle carrying cholesterol to the tissues, it binds to the LDL-receptor and hence facilitates uptake of cholesterol by cells by the process of pinocytosis. Elevation in LDL-cholesterol level and decrease in HDL-cholesterol/LDL-cholesterol ratio increases the risk of coronary heart disease [4, 7-9].

High-density lipoprotein (HDL) is referred to as the 'scavenger form' of cholesterol as it is believed to protect against oxidative processes. Its half-life in plasma is 3-5 days and it is composed of $18 \%$ cholesterol, $2 \%$ triglycerides, 30\% phospholipids and 50\% proteins, which are mainly Apo A-1 (65\%) and Apo A-II (25\%). HDL plays an important role in regulation of triglyceride catabolism and conversion of cholesterol to cholesterol esters by providing Apo C-II for activation and Apo C-III for inhibition of lipoprotein lipase activity. Since HDL transports cholesterol from tissues to the liver, it provides a protection against coronary heart disease development. The ratio of HDL cholesterol to LDL-cholesterol is a useful indicator of the risk of coronary heart disease.

In addition to cholesterol, smoking, age greater than 45 years in males and 55 years in females, diabetes mellitus, hypertension and a family history of coronary vessel diseases are other well-documented traditional risk factors for the development of CHD [4, 7-9, 10].

\section{Non-Traditional (Novel) Risk Factors for CHD Development}

A number of novel risk factors (fig. 2) have been proposed for CHD development. Among these is a whole group of haematological risk factors since they are prothrombotic and play a significant role in development of thrombus hence predisposing to CHD [11-19].

It has been shown that any defect in haemostasis may lead to thrombus formation. Different factors contribute to venous thromboembolism, while others play a role in arterial thromboembolism. The defect may be in the fibrinolytic system, blood vessel walls, circulating platelets or the circulating coagulation factors. Figure 2 presents some of the major aetiological factors in familial thrombophilia which have been investigated in detail and the findings have led to the identification of several novel risk factors for CHD. Some of the factors contributing to the pathogenesis of venous thromboembolism are discussed below.

\section{Prothrombin 20210A Mutation}

Prothrombin (factor II) is the zymogen precursor of thrombin and is directly related to thrombus formation. Any elevation in the level of prothrombin is considered significant for the health of the cardiovascular system. An allele of prothrombin in which a $20210 \mathrm{G} \rightarrow$ A transition occurs in the 3-untranslated region (UTR) of the prothrombin gene results in an increased prothrombin level in plasma and also an increase in prothrombin clotting activity $[20,21]$. Studies have confirmed that in individuals with this allele there is a 2.7 -fold increased risk of venous thrombosis in adults of both sexes and a 4.0-fold increased risk of myocardial infarction in the young age group [22-25]. Though several studies point to a role of prothrombin gene $20210 \mathrm{G} \rightarrow \mathrm{A}$ transition in development of CHD [23-25], some studies fail to show any association [20, 24-26].

\section{Factor V Leiden in CHD}

Factor V Leiden plays a role in stabilization of the growing thrombus and is known to be a common risk factor for venous thrombus formation. An allele of factor V Leiden with an $A \rightarrow G$ substitution at nucleotide 1691 in the exon 10 of factor $V$ gene, results in a substitution $\mathrm{Arg} \rightarrow \mathrm{Gln}$ at position 506. This factor $\mathrm{V}$ Leiden polymorphism occurs in approximately $3 \%$ of the general population and in about $20-50 \%$ of patients with a history of unexplained recurrent venous thrombosis. The presence of the glutamine instead of an arginine residue removes a site in factor $\mathrm{V}$ that is normally cleaved by activated protein $\mathrm{C}$ and is associated with in vitro resistance to activated protein $\mathrm{C}$. This results in defective termination of coagulation by activated protein C. Several well-designed studies confirm an association between factor $\mathrm{V}$ mutation and venous thrombosis and coronary heart disease [24, 27-29]. However, other studies fail to report any association [20,21].

\section{Homocysteine}

Homocysteine, a sulphydryl-containing amino acid, is an intermediate derived from methionine and its normal plasma levels varies from 5 to $15 \mathrm{mmol} / \mathrm{l}$ [30]. Homocysteine is metabolized either by a remethylation pathway which is catalysed by methionine synthase that produces methionine or transulfuration pathway which produces cystathionine and finally cysteine. For the remethylation 
pathway, both vitamin $B_{12}$ and folate are required, since vitamin $B_{12}$ is an essential cofactor for methionine synthase and $\mathrm{N}^{5}$-methyl tetrahydrofolate is the methyl donor in this reaction, catalysed by $\mathrm{N}^{5}, \mathrm{~N}^{10}$ methylene tetrahydrofolate reductase [31]. The transulfuration pathway is activated when an excess of methionine is present or when cysteine synthesis is required [31]. Since the first report of an association between elevated plasma homocysteine and vascular disease in 1969 [32], extensive studies have been carried out and have confirmed this association $[33,34]$. Hyperhomocysteinemia has been shown as a risk factor for both venous and arterial thrombosis [35].

A thermolabile variant of $\mathrm{N}^{5}, \mathrm{~N}^{10}$ methyltetrahydrofolate reductase, produced as a result of a single point mutation at position $677(\mathrm{C} \rightarrow \mathrm{T})$ in the coding region of $\mathrm{N}^{5}, \mathrm{~N}^{10}$ methyltetrahydrofolate binding site, is associated with hyperhomocysteinemia in homozygotes and an increased risk for vascular disease [36]. It is shown to play an important role in thrombotic vascular disease and in the development of atherosclerosis [37-39]. Studies have shown that hyperhomocysteinemia is associated with coronary artery disease, myocardial infarction, peripheral vascular disease, cerebrovascular disease, stroke and an early death from coronary artery disease. It is shown that elevation in the fasting level of homocysteine by $5 \mathrm{mmol} / \mathrm{l}$ increases the incidence of coronary disease by 1.6- to 1.8-fold [40]. In a rare, autosomal recessive disorder, homocystinuria, which results from deficiency of cystathionine $\beta$-synthase associated with elevated levels of homocysteine in blood and urine, the patients develop vascular disease. However, a few prospective studies have failed to show the relationship between homocysteine level and coronary artery disease [14]. The controversial results may be a consequence of genetic variability in different populations.

\section{Fibrinogen in CHD}

Fibrinogen is a major protein in blood plasma occurring at a level of $200-400 \mathrm{mg} / \mathrm{dl}$. It is synthesized in the liver and during the clotting process it is converted to a polymer, fibrin, under the action of thrombin. It also affects blood rheology and platelet aggregation in addition to the blood coagulation process. Several extensive studies have shown that elevated fibrinogen increases the risk of CHD, stroke, myocardial infarction, and peripheral arterial disease [41-43]. In a study on 333 patients it was shown that elevation of $1 \mathrm{mg} / \mathrm{dl}$ of fibrinogen correlated with a twofold increase in probability of death within 6 years. Hence, it is considered an independent and excel- lent risk marker for cardiovascular diseases [42]. Several factors play a role in elevating fibrinogen level and these include cigarette smoking, age, race, sedentary lifestyle, gender, oral contraceptive use, obesity, stress, inflammation and diabetes mellitus. In addition, a few rare mutations in the fibrinogen gene are associated with thrombophilia. On the other hand, factors that reduce fibrinogen include diets rich in omega- 3 and omega -6 fatty acids, exercise, weight reduction, smoking cessation and stress management $[7,10,13,14,17]$.

\section{von Willebrand Factor}

von Willebrand factor has a pro-coagulant activity. It binds to factor VIII and stabilizes coagulation. It is also considered a marker of endothelial cell dysfunction. Elevation in the level of von Willebrand factor has been shown to increase the relative risk of CHD to 1.71 [44-46].

\section{Plasminogen Activator Inhibitor Type I}

The plasminogen activator inhibitor type-1 (PAI-1) inhibits the conversion of plasminogen to plasmin and hence inhibits fibrinolysis as it disrupts dissolution of thrombus. As PAI-1 frequently occurs in patients with thrombotic disease, it has been considered an important aetiological factor in the development of CHD.

\section{Other Cogulation Factors}

Several studies have been carried out on other coagulation factors and their roles in the development of CHD [23, 48, 49]. These include factors II, V, VII and X. In a study measuring the levels of factors II, V, VII, and X, it was shown that in patients with myocardial infarction the levels of these factors are significantly elevated $(p<0.05)$. The relative risk of myocardial infarction was calculated as only 1.0 for factor II, and 3.3, 5.2, 2.2, for factors V, VII and $\mathrm{X}$, respectively. High clotting activity of factor VII is shown to be significantly associated with an increased risk of CHD.

Since thrombophilia is shown to be closely related to the risk of developing CHD, any factor which increases the tendency to form thrombus, such as an ongoing stimulus to thrombogenesis, or a defect in natural anticoagulant activity or a defect in fibrinolytic mechanism plays a role in predisposing to $\mathrm{CHD}$. 


\section{Other Inherited Defects Leading to Thrombophilia and Possibly CHD}

Some inherited defects that have been shown to play a role in the development of thrombophilia include deficiency in antithrombin III, protein $\mathrm{C}$, protein $\mathrm{S}$ and activated protein $\mathrm{C}$ resistance [50]. Antithrombin III deficiency is a rare disorder, inherited as an autosomal dominant trait. In patients with combined deficiency of protein $\mathrm{C}$ and antithrombin III, both arterial and venous thrombosis have been reported. However, some studies fail to show an association between these factors and risk of coronary events [44]. In the heterozygotes the AT III level is $50 \%$ of normal, while homozygous state is incompatible with life. Increase in the frequency of both arterial and venous thromboembolic state in adults and children have been reported [51]. In patients with a novel nonsense mutation in the antithrombin III gene (Cys $4 \rightarrow$ stop) recurrent venous thrombosis has been reported [52].

Protein $\mathrm{C}$ deficiency is more common and is reported in 1:1,350 blood donors. It also exists as an autosomaldominant disorder and increases the risk of both arterial and venous thromboembolism by severalfolds. The homozygous state is associated with neonatal purpura. In addition, plasminogen deficiency and reduced plasminogen activator activity also play a role in thrombophilia. Almost $20-60 \%$ of patients with thrombophilia are shown to have activated protein $\mathrm{C}$ resistance. This is strongly related to the generation of thrombus.

\section{Role of Infections in CHD}

Several infectious agents have been implicated in the development of atherosclerotic lesions. These include Chlamydia pneumoniae, Helicobacter pylori and Cytomegalovirus (CMV). C. pneumoniae is a common bacterium that infects a large percentage of the population at some time in their lives. It causes almost $10 \%$ of all pneumonias and has a role in the pathology of acute asthma and chronic bronchitis. Studies have shown the presence of $C$. pneumoniae in the atherosclerotic lesions of coronary arteries, carotid arteries, the aorta, smaller cerebral vessels and larger peripheral arteries [53, 54]. In addition, studies have documented rising or elevated levels of antibodies to this bacterium in some patients during the months just preceding a heart attack [55]. Treatment with antibiotics after a first heart attack has been shown to reduce the risk of a second attack [56].

H. pylori, as organism most frequently associated with gastrointestinal infections [57], and Cytomegalovirus (CMV), a common viral infection that is usually silent and self-limited, have also been implicated in the development of CHD.

\section{Conclusion}

Hematological risk factors constitute an important group of the novel (nontraditional) risk factors for $\mathrm{CM}$ development and require careful monitoring in high-risk groups and in patients on therapy such as those on cancer therapy, or hormonal treatment for infertility since these predispose to thrombophilia and hence may precipitate CHD.

\section{References}

1 La Rosa JC: Future cardiovascular endpoint studies: Where will the research take us? Am J Cardiol 1999;84:545-548.

2 Kannel WB, McGee DL: Diabetes and cardiovascular risk factors: The Framingham Study. Circulation 1979;59:8-13.

3 Saito I, Folsom AR, Brancati FL, Duncan BB, Chambless LE, McGovern PG: Nontraditional risk factors for coronary heart disease incidence among persons with diabetes: The atherosclerosis risk in communities (ARIC) study. Ann Intern Med 2000;133:81-91.

4 Catanzaro AJ, Suen R: Clinical laboratory indicators of cardiovascular disease risk. Alt Med Rev 1996;1:185-194.
5 Rauch U, Osende JL, Fuster V, Badimon JJ, Fayad Z, Chesebro JH: Thrombus formation on atherosclerotic plaques: Pathogenesis and clinical consequences. Ann Intern Med 2000; 134:224-238.

6 Gensini GF, Comeglio M, Colella A: Classical risk factors and emerging elements in the risk profile for coronary artery disease. Eur Heart J 1998;19(suppl A):A53-61.

7 Berg K: Genetics of coronary heart disease and its risk factors. Ciba Found Symp 1987;130: 14-33.

8 Neufeld HN, Goldbourt U: Coronary heart disease: Genetic aspects. Circulation 1983;67: 943-954.

9 Sing CF, Moll PP: Genetics of variability of CHD risk. Int J Epidemiol 1989;18:S183S195.
10 Pereira MA, Schreiner PJ, Pankow JS, Williams RR, Higgins M, Province MA, Rao DC: The family risk score for coronary heart disease: Association with lipids, lipoproteins, and body habitus in a middle-aged bi-racial cohort. The ARIC study. Ann Epidemiol 2000;10: 239-245.

11 Ince $\mathrm{B}$, Bayram $\mathrm{C}$, Harmanci $\mathrm{H}$, Ulutin $\mathrm{T}$ : Hemostatic markers in ischemic stroke of undetermined etiology. Thromb Res 1999;96: 169-174.

12 Feinberg WM, Bruck DC, Ring ME, Corrigan JJ Jr: Hemostatic markers in acute stroke. Stroke 1989;20:592-597.

13 Takano K, Yamaguchi T, Uchida K: Markers of a hypercoagulable state following acute ischemic stroke. Stroke 1992;23:194-198. 
14 Folsom AR: New 'risk factors' for atherosclerotic disease. Exp Gerontol 1999;4:483-490.

15 Feinberg WK, Erickson LP, Bruck D, Kittelson $\mathrm{J}$ : Hemostatic markers in acute ischemic stroke: Association with stroke type, severity and outcome. Stroke 1996;27:1296-1300.

16 Fisher M, Francis R: Altered coagulation in cerebral ischemia: Platelet, thrombin, and plasmin activity. Arch Neurol 1990;47:10751079.

17 Deguchi K, Deguchi A, Wada H, Murashima S: Study of cardiovascular risk factors and hemostatic molecular markers in elderly persons. Semin Thromb Hemost 2000;26:23-27.

18 Fon EA, Mackey A, Cote R, Wolfson C, Mellraith DM, Leclerc J, Bourque F: Hemostatic markers in acute transient ischemic attacks. Stroke 1994;25:282-286.

19 Omo N, Koyama T, Suehiro A, Oku K, Fujikake K, Kakishita E: Clinical significance of new coagulation and fibrinolytic markers in ischemic stroke patients. Stroke 1991;22: 1369-1373

20 Redondo M, Watzke HH, Stucki I, Sulzer I, Biasiutti FD, Binder BR, Furlan M, Lammle B, Wuillemin WA: Coagulation factors II, V, VII, and $\mathrm{X}$, prothrombin gene $20210 \mathrm{G}-\mathrm{A}$ transition, and factor $\mathrm{V}$ Leiden in coronary artery disease. Arterioscler Thromb Vasc Biol 1999; 19:1020-1025.

21 Cushman M, Lemaitre LH, Kuller LH, Psaty BM, Macy EM, Sharrett AR, Tracy RP: Fibrinogen activation markers predict myocardial infarction in the elderly: The cardiovascular health study. Arterioscler Thromb Vasc Biol 1999;19:493-498.

22 Ehrenforth S, von Depka Prondsinski M, Aygoren-Pursun E, Nowak-Gottl U, Scharrer I, Ganser A: Study of the prothrombin gene 20201 GA variant in FV: $Q^{50-6}$ carriers in relationship to the presence or absence of juvenile venous thromboembolism. Arterioscler Thromb Vasc Biol 1999;19:276-280.

23 Giannitsis E, Siemens HJ, Mitusch R, Tettenborn I, Wiegand U, Schmucker G, Sheikhzadeh A, Stierle U: Prothrombin fragments F $1+$ 2, thrombin-antithrombin III complexes, fibrin monomers and fibrinogen in patients with coronary atherosclerosis. Int J Cardiol 1999;68: 269-274.

24 Gardemann A, Arsic T, Katz N, Tillmanns H, Hehrlein FW, Haberbosch W: The factor II G20210A and factor V G1691A gene transitions and coronary heart disease. Thromb Haemost 1999;81:208-213.

25 Nguyen A: Prothrombin G20210A polymorphism and thrombophilia. Mayo Clin Proc 2000;75:595-604.

26 Corral J, Gonzalez-Conejero R, Lozano ML, Rivera J, Heras I, Vicente V: The venous thrombosis risk factor 20210A allele of the prothrombin gene is not a major risk factor for arterial thrombotic disease. Br J Haematol 1997;99:304-307.

27 Svensson PJ, Dahlback B: Resistance to activated protein $\mathrm{C}$ is a basis for venous thrombosis. N Engl J Med 1994;330:517-522.
28 Bertina RM, Koeleman BP, Koster T, Rosendaal FR, Dirven RJ, de Ronde H, van der Velden PA, Reitsma PH: Mutation in blood coagulation factor $\mathrm{V}$ associated with resistance to activated protein C. Nature 1994;369:64-67.

29 Ridker PM, Hennekens CH, Lindpaintner K, Stampfer MJ, Eisenberg PR, Miletich JP: Mutation in the gene coding for coagulation factor $\mathrm{V}$ and the risk of myocardial infarction, stroke, and venous thrombosis in apparently healthy men. N Engl J Med 1993;332:912917.

30 Ueland PM, Refsun H, Stabler SP, Mailinow MR, Andersson A, Allen RH: Total homocysteine in plasma or serum: Methods and clinical applications. Clin Chem 1993;39:1764-1779.

31 Finkelstein JD, Martin JJ, Harris BJ: Methionine metabolism in mammals: The methionine sparing effect of cystine. J Biol Chem 1988; 263;11750-11754.

32 McCully KS: Vascular pathology of homocysteine: Implications for the pathogenesis of arteriosclerosis. Am J Pathol 1969;56:111-128.

33 Ueland PM, Refsum H: Plasma homocysteine, a risk factor for vascular disease: Plasma levels in health, disease and drug therapy. J Lab Clin Mod 1989;114:473-501.

34 McCully KS: Homocysteine and vascular disease. Nat Med 1996;2:386-389.

35 Kang SS, Wong PW, Malinow M: Hyperhomocysteinemia as a risk factor for occlusive vascular disease. Am Rev Nutr 1992;12:279-298.

36 Deloughery TG, Evans A, Sadeglu A, McWilliams J, Henner WD, Taylor LM Jr: Common mutations in methylene tetrahydrofolate reductase: Correlation with homocysteine metabolism and late onset vascular disease. Circulation 1996:3074-3078.

37 Clarke R, Daly L, Robinson K, Naughten E, Cahalane S, Fowler B, Graham I: Hyperhomocysteinemia: An independent risk factor for vascular disease. N Engl J Med 1991;324: 1149-1155.

38 Glueck CJ, Shaw P, Lang JE, Tracy T, SteveSmith L, Wang Y: Evidence that homocysteine is an independent risk factor for atherosclerosis in hyperlipidemia patients. Am J Cardiol 1995; 75:132-136.

39 Amesen E, Refsum H, Bonaa KH, et al: Serum total homocysteine and coronary heart disease. Int J Epidemiol 1995;24:704-709.

40 Welch GN, Loscalzo J: Homocysteine and atherosclerosis. N Engl J Med 1998;338:10421049.

41 Anand A: Fibrinogen and cardiovascular risk. Ann Intern Med 1993;119:1222-1223.

42 Ernst E: Fibrinogen: An important risk factor for atherosclerotic diseases. Ann Med 1994;26: $15-22$.

43 Hamsten A, Iselius L, de Faire U, Blomback M: Genetic and cultural inheritance of plasma fibrinogen concentration. Lancet 1987;ii:988991.
44 Folsom AR, Rosamond WD, Shahar E, Cooper LS, Aleksic N, Nieto FJ, Rasmussen ML, Wu KK: Prospective study of markers of hemostatic function with risk of ischemic stroke: The Atherosclerosis Risk in Communities (ARIC) Study Investigators. Circulation 1999;100: 736-742.

45 Saito I, Folsom AR, Brancati FL, Duncan BB Chambless LE, McGovern PG: Nontraditional risk factors for coronary heart disease incidence among persons with diabetes: The Atherosclerosis Risk in Communities (ARIC) Study. Ann Intern Med 2000;133:81-91

46 Wiman B, Andersson T, Hallqvist J, Reuterwall C, Ahlbom A, deFaire U: Plasma levels of tissue plasminogen activator/plasminogen activator inhibitor-1 complex and von Willebrand factor are significant risk markers for recurrent myocardial infarction in the Stockholm Heart Epidemiology Program (SHEEP) study. Arterioscler Thromb Vasc Biol 2000;20:2019-2023.

47 Wiman B: Plasminogen activator inhibitor I (PAI) in plasma: Its role in thrombotic disease. Thromb Haemost 1995;74:71-76.

48 Altes A, Abellan MT, Mateo J, Avila A, MartiVilalta JL, Fontcuberta J: Hemostatic disturbances in acute ischemic stroke: A study of 86 patients. Acta Haematol 1995;94:10-15.

49 Takano K, Yamaguchi T, Uchida K: Markers of a hypercoagulable state following acute ischemic stroke. Stroke 1992;23:194-198.

$50 \mathrm{Wu}$ KK: Genetic markers: Genes involved in thrombosis. J Cardiovasc Risk 1997;4:347352.

51 Sansores-Garcia L, Majluf-Cruz A: Arterial and venous thrombosis associated to combined deficiency of protein $\mathrm{C}$ and antithrombin III. Am J Hematol 1998;57:182-183.

52 Saleun S, De Moerloose P, Bura A, Aiach M, Emmerich J: A novel nonsense mutation in the antithrombin III gene (Cys-4 $\rightarrow$ stop) causing recurrent venous thrombosis. Blood Coagul Fibrinolysis 1996;7:578-579.

53 Maass M: Persistence of Chlamydia pneumoniae in human atherosclerotic plaques material: Evidence and consequences. Herz 1998;23: 178-184.

54 Mehra JL, Saldeen TG, Rand K: Interactive role of infection, inflammation and traditional risk factors in atherosclerosis and coronary artery disease. J Am Coll Cardiol 1998;31:12171225 .

55 Mazzoli S, Tofani N, Fantini A, Semplici F, Bandini F, Salvi A, Vergassola R: Chlamydia pneumoniae antibody response in patients with acute myocardial infarction and their followup. Am Heart J 1998;135:15-20.

56 Gurfinkel E, Bozovich G, Beck E, Testa E, Livellara B, Maunter B: Treatment with the antibiotic roxithromycin in patients with acute non-Q-wave coronary syndromes: The final report of the ROXIS study. Eur Heart J 1999;20: 121-127.

57 Pasceri V, Cammarota G, Patti G, Cucco L, Gasbarrini A, Grillo RL, Fedeli G, Gasbarrini G, Maseri A: Association of virulent Helicobacter pylori strains with ischemic heart disease. Circulation 1998;97:1675-1679. 